\title{
Impact of Bioelectronic Medicine on the Neural Regulation of Pelvic Visceral Function
}

\author{
William C de Groat ${ }^{1}$ and Changfeng Tai ${ }^{1,2}$ \\ Departments of ${ }^{1}$ Pharmacology and Chemical Biology and ${ }^{2}$ Urology, University of Pittsburgh Medical School, Pittsburgh, \\ Pennsylvania, United States of America
}

\begin{abstract}
Neuromodulation elicited by electrical stimulation of peripheral or spinal nerves is a U.S. Food and Drug Administered (FDA)-approved therapy for treating disorders of the pelvic viscera, including urinary urgency, urgency-frequency, nonobstructive urinary retention and fecal incontinence. The technique is also being tested experimentally for its efficacy in treating interstitial cystitis, chronic constipation and pelvic pain. The goal of neuromodulation is to suppress abnormal visceral sensations and involuntary reflexes and restore voluntary control. Although detailed mechanisms underlying the effects of neuromodulation are still to be elucidated, it is generally believed that effects are due to stimulation of action potentials in somatic afferent nerves. Afferent nerves project to the lumbosacral spinal cord, where they release excitatory neurotransmitters that activate ascending pathways to the brain or spinal circuits that modulate visceral sensory and involuntary motor mechanisms. Studies in animals revealed that different types of neuromodulation (for example, stimulation of a sacral spinal root, pudendal nerve or posterior tibial nerve) act by releasing different inhibitory and excitatory neurotransmitters in the central nervous system. In addition, certain types of neuromodulation inhibit visceral smooth muscle by initiating reflex firing in peripheral autonomic nerves or excite striated sphincter muscles by initiating reflex firing in somatic efferent nerves. This report will provide a brief summary of (a) neural control of the lower urinary tract and distal bowel, (b) clinical use of neuromodulation in the treatment of bladder and bowel dysfunctions, (c) putative mechanisms of action of neuromodulation on the basis of animal experiments and (d) new approaches using combination therapies to improve the efficacy of neuromodulation.
\end{abstract}

Online address: www.bioelecmed.org

doi: 10.15424/bioelectronmed.2015.00003

\section{INTRODUCTION}

The pelvic visceral organs perform essential excretory and sexual functions that are mediated by complex neural circuitry in the brain and spinal cord. Accordingly, injuries or diseases at various sites in the nervous system can produce prominent changes in micturition, defecation and sexual activity. The pelvic organs have a similar peripheral afferent and efferent innervation that originates at the lumbosacral level of the spinal cord (Fig. 1) (1-3). The organs also exhibit unique properties not shared by other visceral organs, including (a) complete dependence on central neural control, (b) excretory and sexual functions that are initiated in an all-or-none or switch-like manner, (c) functions that depend on coordination between multiple smooth and striated muscles and (d) voluntary control of micturition and defecation in contrast to the involuntary control of other visceral organs.

Address correspondence to William C de Groat, Department of Pharmacology and Chemical Biology, 200 Lothrop Street, W-1352 Starzl Biomedical Science Tower, University of Pittsburgh Medical School, Pittsburgh, PA 15261. Phone: 412-648-9357; Fax: 412-648-1945; Email: wcd2@pitt.edu.

Submitted January 20, 2015; Accepted for publication January 22, 2015; Published Online (www.bioelecmed.org) January 22, 2015

\section{The Feinstein Institute for Medical Research} Empowering Imagination. Pioneering Discovery.

Disorders of the lower urinary tract and distal bowel, such as overactive bladder syndrome $(\mathrm{OAB})$, nonobstructive urinary retention, constipation and fecal incontinence, are commonly treated with behavioral therapy or drugs (4); however, when patients are refractory to these first-line treatments or when treatment has to be terminated because of side effects, neuromodulation elicited by electrical stimulation of spinal nerve roots or peripheral nerves is often used $(5,6)$. Sacral neuromodulation is a U.S. Food and Drug Administered (FDA)-approved therapy that involves permanent implantation of electrodes on spinal nerves at the sacral level along with implantation of a stimulator and battery at a more distant site (7). Stimulation is usually applied continuously to obtain the optimal beneficial effects. Another type of FDA-approved office-based minimally invasive therapy involves stimulation of the posterior tibial nerve with electrodes inserted percuta- 


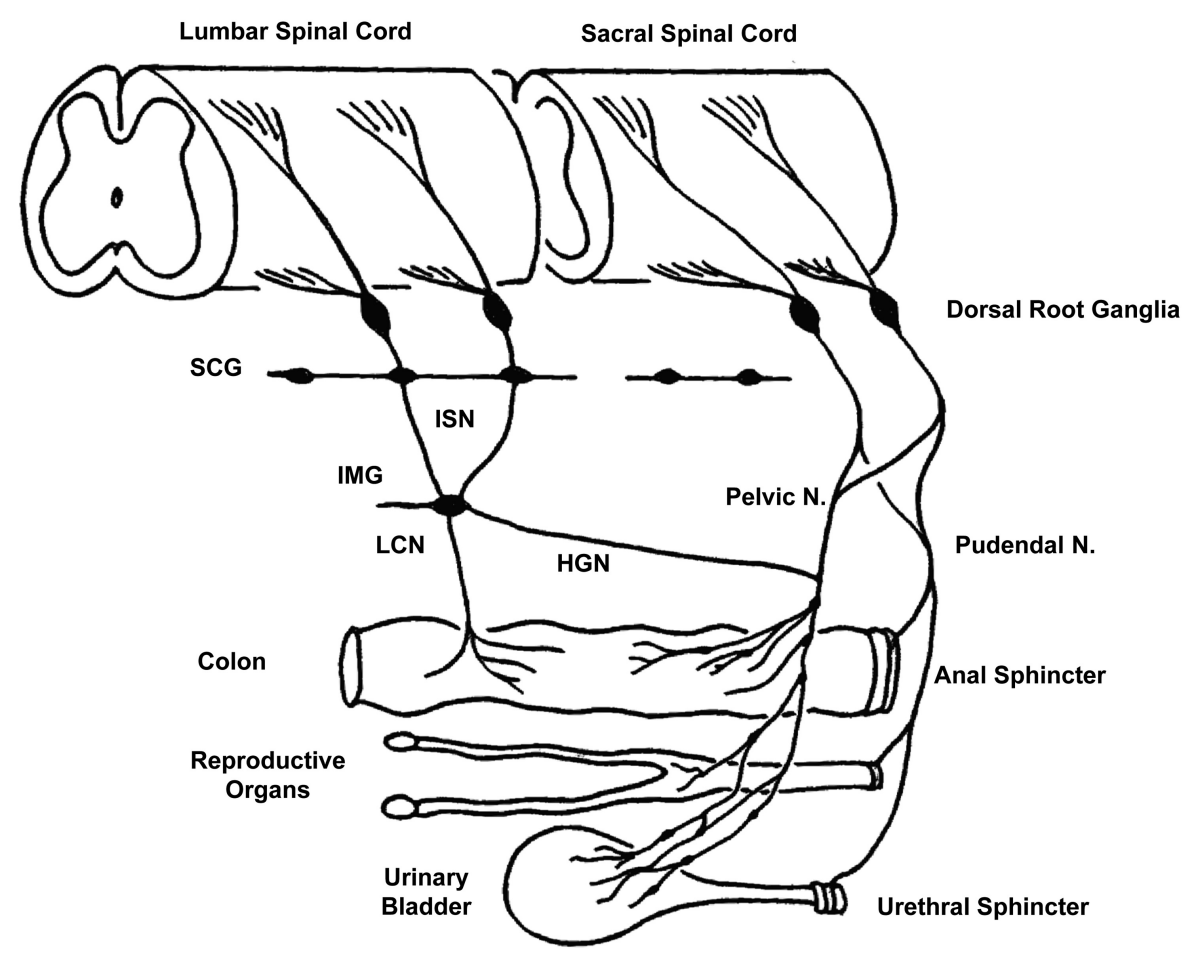

Figure 1. Diagram shows the peripheral pathways for afferent innervation of the pelvic viscera in the cat. Neurons in the sacral dorsal root ganglia send axons into the pelvic and pudendal nerves. The pelvic nerves innervate exclusively the viscera, whereas the pudendal nerves innervate visceral as well as somatic structures such as the anal and urethral sphincters and the perineum. Neurons in the lumbar dorsal root ganglia send axons into the lumbar colonic nerve (LCN) and hypogastric nerve (HGN). The latter axons pass through the sympathetic chain ganglia (SCG) and then the inferior splanchnic nerves (ISN) to the inferior mesenteric ganglia (IMG). The HGN passes caudally to join the pelvic nerve.

neously for each treatment (8). Stimulation is applied for 30 min every week for 12 wks followed by 30-min booster treatments at 2- to 4-wk intervals.

Experimental neuromodulation methods include (a) transcutaneous posterior tibial nerve stimulation with electrodes applied to the surface of the leg (9), (b) pudendal nerve stimulation with implanted or percutaneous electrodes (10), (c) transcutaneous foot stimulation with electrodes applied to the plantar surface (11), (d) electrical stimulation of the bladder via electrodes inserted through the urethra into the bladder lumen (12), (e) electrical stimulation of the urethra via electrodes inserted into the urethral lumen (13) and (f) electrical stimulation of the dorsal genital nerve $(14,15)$. Sacral anterior root stimulation via permanently implanted electrodes, a technique developed by Brindley in the 1970s, is used to elicit emptying of the bladder or colon or penile erection in people with complete suprasacral spinal cord injuries (16).

Although the detailed mechanisms underlying the effects of commonly used neuromodulation methods are still to be elucidated; it is generally believed that beneficial effects are due to the initiation of action potentials in somatic afferent nerves. Afferent nerves then project to the lumbosacral segments of the spinal cord, where they release neurotransmitters that modulate abnormal visceral sensations and/or involuntary motor mechanisms by activating either spinal reflex circuits or ascending pathways to the brain. This report will provide a brief overview of the neural control of the pelvic viscera with a particular focus on bladder and bowel, how neural control is altered in pathological conditions and the putative mechanisms that underlie the normalization of bladder and bowel functions by neuromodulation.

\section{NEURAL CIRCUITRY CONTROLLING THE PELVIC VISCERA}

\section{Peripheral Nervous System}

The pelvic organs receive a bilateral efferent innervation from the thoracic and lumbosacral segments of the spinal cord (Figures 1 and 2). Efferent axons are carried in three sets of peripheral nerves: sacral parasympathetic (pelvic nerves), thoracolumbar sympathetic nerves (hypogastric nerves and sympathetic chain) and sacral somatic nerves (primarily the pudendal nerves (Figure 1). Preganglionic axons carrying information from the spinal cord synapse with autonomic ganglion cells widely distributed throughout the peripheral nervous system in (a) the pelvic plexus (Figure 2A), (b) prevertebral sympathetic ganglia (inferior mesenteric ganglia), (c) paravertebral sympathetic chain ganglia and (d) ganglia on the serosal surface and in the wall (intramural ganglia) of the organs $(17,18)$. The bowel also has an intrinsic (enteric) nervous system that contains sensory and motor elements that can generate local reflexes independent of input from the central nervous system. The proximal large bowel also receives input from efferent axons traveling from the brainstem in the vagus nerve (2). However, this pathway is not involved in defecation. The striated muscles of the external urethral sphincter (EUS), the external anal sphincter (EAS) and the bulbocavernous and ischiocavernous muscles that mediate ejaculation are directly innervated by excitatory cholinergic axons originating from motoneurons in the spinal cord $(1,19)$.

Excitatory parasympathetic neuroeffector transmission in the bladder and bowel is mediated by acetylcholine acting on postjunctional muscarinic receptors (Figure 2B) $(1,20)$, whereas parasympathetic input to the penis inducing penile 


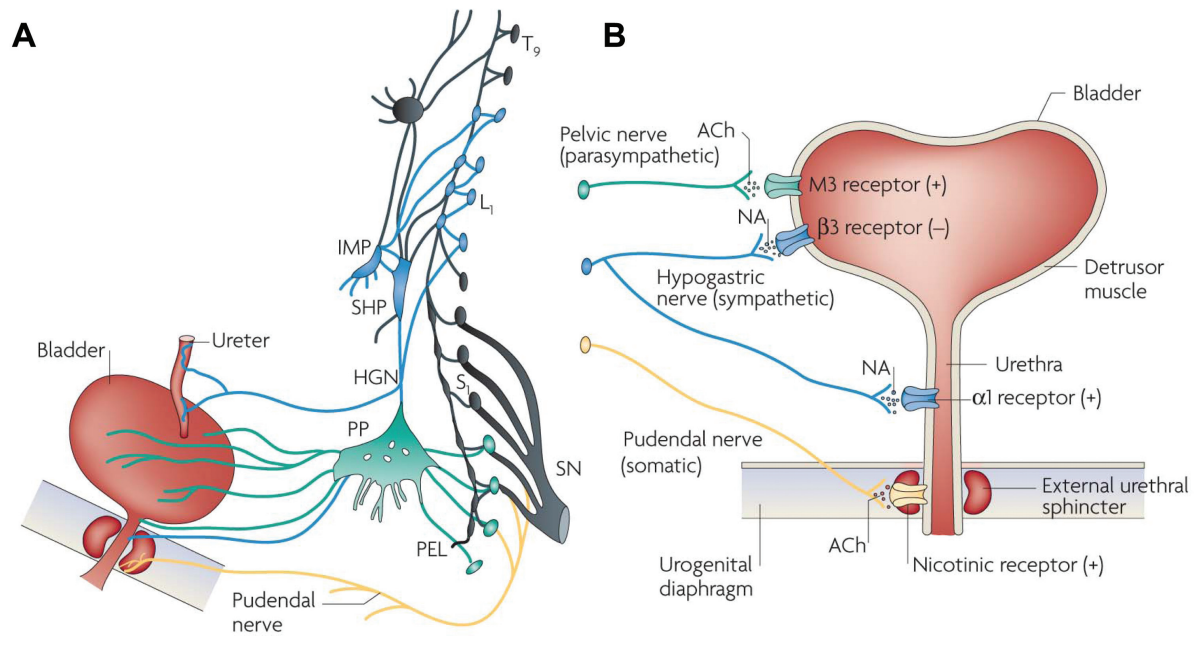

Figure 2. Efferent pathways of the lower urinary tract. (A) Innervation of the female lower urinary tract. Sympathetic fibers (shown in blue) originate in the T1 1-L2 segments in the spinal cord and run through the inferior mesenteric ganglia (inferior mesenteric plexus (IMP)) and the hypogastric nerve $(\mathrm{HGN})$ ) or through the paravertebral chain to enter the pelvic nerves at the base of the bladder and urethra. Parasympathetic preganglionic fibers (shown in green) arise from the S2-S4 spinal segments and travel in sacral roots and pelvic nerves (PEL) to ganglia in the pelvic plexus (PP) and in the bladder wall. This is where the postganglionic nerves that supply parasympathetic innervation to the bladder arise. Somatic motor nerves (shown in yellow) that supply the striated muscles of the EUS arise from S2-S4 motor neurons and pass through the pudendal nerves. (B) Efferent pathways and neurotransmitter mechanisms that regulate the lower urinary tract. Parasympathetic postganglionic axons in the pelvic nerve release acetylcholine (ACh), which produces a bladder contraction by stimulating $\mathrm{M}_{3}$ muscarinic receptors in the bladder smooth muscle. Sympathetic postganglionic neurons release noradrenaline (NA), which activates $\beta_{3}$ adrenergic receptors to relax bladder smooth muscle and activates $\alpha_{1}$ adrenergic receptors to contract urethral smooth muscle. Somatic axons in the pudendal nerve also release ACh, which produces a contraction of the external sphincter striated muscle by activating nicotinic cholinergic receptors. Parasympathetic postganglionic nerves also release ATP, which excites bladder smooth muscle, and nitric oxide, which relaxes urethral smooth muscle (not shown). $L_{1}$, first lumbar root; $\mathrm{S}_{1}$, first sacral root; SHP, superior hypogastric plexus; $S N$, sciatic nerve; $T_{9}$, ninth thoracic root. Reprinted with permission from (20): Fowler CJ, Griffiths D, de Groat WC. (2008) The neural control of micturition. Nat. Rev. Neurosci. 9:453-66.

erection is mediated by nitric oxide (3). Nitric oxide is also involved in parasympathetic nerve-induced relaxation of the smooth muscle of the urethra $(1,20)$ and anal canal (2). Sympathetic nerves relax bladder and colonic smooth muscle by releasing norepinephrine, which activates $\beta$ adrenergic receptors and contracts smooth muscle of the urethra, anal canal and vas deferens by activating $\alpha$ adrenergic receptors (Figure 2B) (1-3).

Afferent axons in the pelvic, hypogastric and pudendal nerves transmit information from the pelvic organs to secondorder neurons in the lumbosacral spinal cord. Afferents that innervate the lower urinary tract and distal bowel originate in caudal lumbosacral dorsal root ganglia (DRG) (Figure 1) and are divided into two

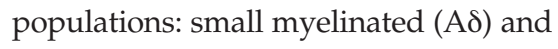
unmyelinated C-fibers (21). The pudendal nerves also contain larger-diameter myelinated afferents that innervate the penis, clitoris and striated sphincters $(3,19)$.

\section{Spinal Cord}

The reflex circuitry controlling micturition consists of four basic components: primary afferent neurons, spinal efferent neurons, spinal interneurons (Figures 3B,
C) and neurons in the brain that activate or modulate spinal reflex pathways. Sacral afferent pathways passing through the pelvic nerve project into Lissauer tract at the apex of the dorsal horn and then send collaterals laterally and medially around the dorsal horn to interneurons in the dorsal commissure (lamina X) and to the sacral parasympathetic nucleus in laminae V-VII, which contain parasympathetic preganglionic neurons and interneurons (Figure 3A) $(1,20,21)$. EUS and EAS motoneurons are located in Onuf nucleus (lamina IX) (Figure 3D). Pudendal nerve afferent pathways from the EUS and EAS have central terminations that overlap with those of pelvic nerve afferents (19), whereas other populations of pudendal nerve afferents innervating the sex organs and perineum terminate in the deeper layers of the dorsal horn (laminae II-IV). Interneurons that are part of spinal reflex circuits can make excitatory or inhibitory synaptic connections with preganglionic neurons (22-24) and motoneurons (25), whereas others project to the brain and are a part of ascending sensory pathways and supraspinal reflex mechanisms $(25,26)$.

\section{Reflex Mechanisms}

The reflex mechanisms controlling the three major pelvic visceral functions are organized differently. Sexual functions, including penile erection, seminal emission and ejaculation, are mediated by spinal reflexes triggered by penile afferents in the pudendal nerve and modulated by facilitatory and inhibitory inputs from the brain $(3,27)$. Neural control of the lower urinary tract consists of urine storage and voiding mechanisms (Figures 4A, B). Efficient urine storage, which requires a quiescent bladder and a closed urethral outlet, is promoted by spinal reflexes that activate sympathetic inhibitory input to the bladder and sympathetic excitatory input to the urethra in parallel with pudendal nerve excitatory input to the EUS (Figure 4A) (1). During micturition, these spinal storage reflexes are inhibited by input from the brain in parallel with activation of the sacral 
A

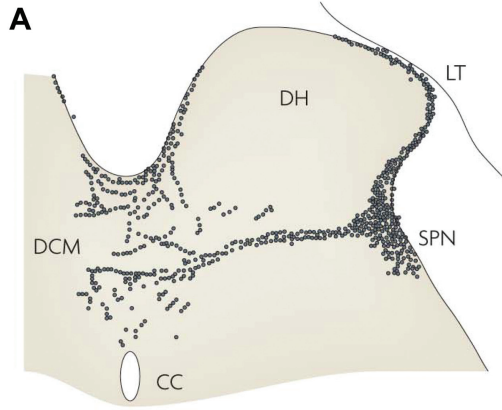

C.

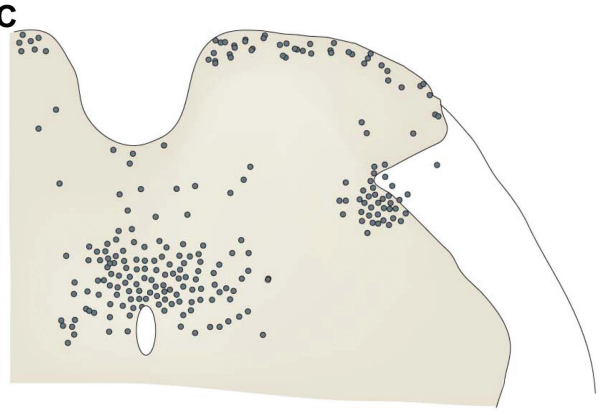

B

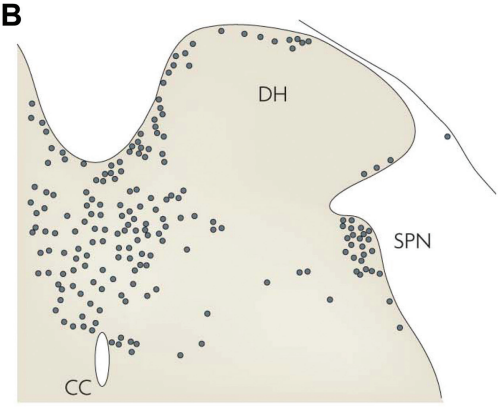

D

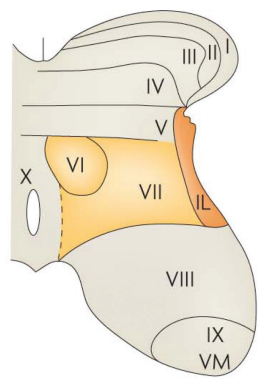

Figure 3. Primary afferent and spinal interneuronal pathways involved in micturition. (A) Primary afferent pathways to the L6 spinal cord of the rat project to regions of the dorsal commissure (DCM), the superficial dorsal horn (DH) and the sacral parasympathetic nucleus (SPN) that contain parasympathetic preganglionic neurons. The afferent nerves

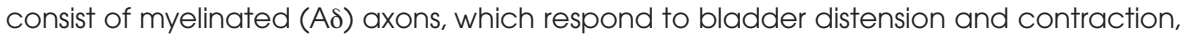
and unmyelinated (C) axons, which respond to noxious stimuli. (B) Spinal interneurons that express $c$-fos after the activation of bladder afferents by a noxious stimulus (acetic acid) to the bladder are located in similar regions of the L6 spinal segment. (C) Spinal interneurons involved in bladder reflexes (labeled by transneuronal transport of pseudorabies virus injected into the urinary bladder) are localized to the regions of the spinal cord that contain primary afferents and c-fos. Some of these interneurons provide excitatory and inhibitory inputs to the parasympathetic preganglionic neurons located in the SPN. (D) The laminar organization of the cat sacral spinal cord, showing the location of parasympathetic preganglionic neurons in the intermediolateral region of laminae $\mathrm{V}$ and VII (shaded area). CC, central canal; IL, intermediolateral nucleus; LT, Lissauer tract; VM, ventromedial nucleus (Onuf nucleus). Reprinted with permission from (20): Fowler CJ, Griffiths D, de Groat WC. (2008) The neural control of micturition. Nat. Rev. Neurosci. 9:453-66.

parasympathetic excitatory pathway to the bladder, mediated by a long loop spinal-brain-spinal pathway that is triggered by bladder distension and activation of Ad mechano-sensitive bladder afferents $(1,28-30)$. This supraspinal micturition pathway passes through relay stations in the sacral spinal cord, the periaqueductal gray (PAG) and the pontine micturition center (PMC) (Figure $4 B)(1,20)$. The pathway functions as an on-off switching circuit (31) that changes the motor control of the lower urinary tract in an all-or-nothing manner from storage to voiding. A computer model of the PAG-PMC switching circuitry that is based on electrophysiological and pharmacological data obtained during in vivo experiments and that consists of tonically active inhibitory neurons in addition to reciprocal inhibition between excitatory and inhibitory pathways (Figure 5) mimics the reflex properties of the bladder and urethra. The PAG-PMC switch is in turn regulated by input from the forebrain, which is responsible for the voluntary control of micturition (Figure 6) (1).

Storage of feces is facilitated by tonic contraction of the EAS in concert with lumbar sympathetic inhibitory control of the colon and excitatory control of the smooth muscle of the anal canal $(2,32)$. Defecation is mediated by a spinal reflex mechanism that has an afferent limb in the pelvic nerve activated by colonic distension and an efferent limb in the pelvic nerve that carries sacral parasympathetic excitatory input to the colonic smooth muscle and myenteric plexus $(2,33,34)$. The defecation reflex receives facilitatory input from neurons in the region of the PMC (35) but persists after transection of the spinal cord at a suprasacral level that eliminates the descending input (33). Penile erection also persists after a similar transection of the spinal cord $(3,27)$, whereas the micturition reflex is eliminated after cord transection that interrupts the supraspinal pathway (28-30). However, reflex bladder contractions recover several weeks after cord transection because of reorganization of spinal circuitry, sensitization of bladder afferent nerves and formation of a new micturition reflex pathway that is activated by C-fiber bladder afferents (Figure 7) $(21,29,30,36)$.

\section{MECHANISMS OF NEUROMODULATION}

Neuromodulation of pelvic organ functions induced by electrical stimulation of sacral spinal nerve roots or peripheral nerves originating in the lumbosacral segments of the spinal cord is attributable to activation of action potentials in afferent axons that propagate into the spinal cord. Based on the electrical thresholds for inducing neuromodulation, it is likely that large diameter myelinated afferent axons are the target of stimulation rather small myelinated $\mathrm{A} \delta$ and $C$ fiber visceral afferent axons that have high electrical thresholds exceeding the stimulus intensities used for neuromodulation (37). These observations indicate that neuromodulation must be mediated by activation of large afferent axons that innervate muscle, skin or other nonvisceral tissues.

Because all primary afferents are known to release excitatory neurotransmitters, it is assumed that the second step in the initiation of neuromodulation 


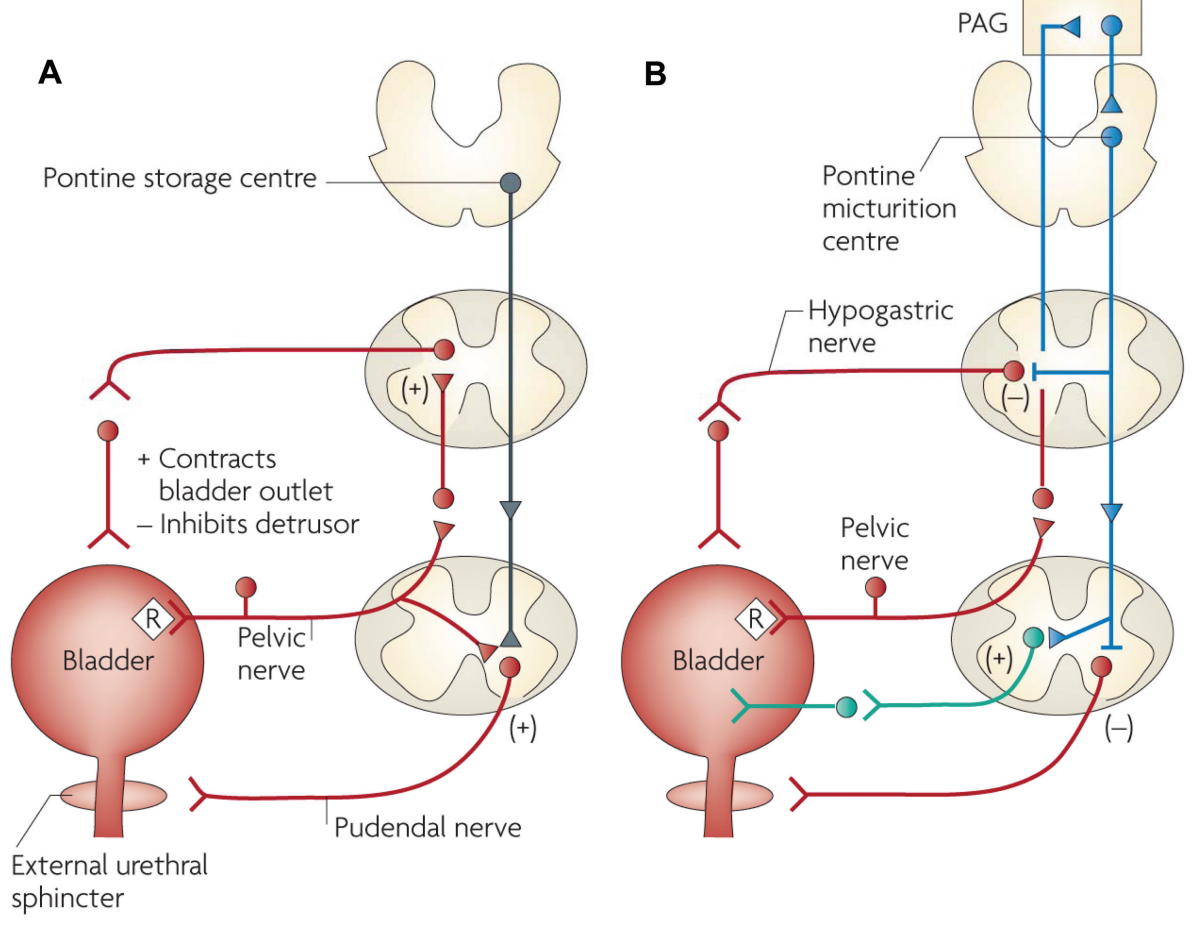

Figure 4. Neural circuits that control continence and micturition. (A) Urine storage reflexes. During the storage of urine, distention of the bladder produces low-level vesical afferent firing. This in turn stimulates the sympathetic outflow in the hypogastric nerve to the bladder outlet (the bladder base and the urethra) and the pudendal outflow to the EUS. These responses occur by spinal reflex pathways and represent guarding reflexes, which promote continence. Sympathetic firing also inhibits contraction of the detrusor muscle and modulates neurotransmission in bladder ganglia. A region in the rostral pons (the pontine storage center) might increase striated urethral sphincter activity. (B) Voiding reflexes. During the elimination of urine, intense bladder-afferent firing in the pelvic nerve activates spinobulbospinal reflex pathways (shown in blue) that pass through the pontine micturition center. This stimulates the parasympathetic outflow to the bladder and to the urethral smooth muscle (shown in green) and inhibits the sympathetic and pudendal outflow to the urethral outlet (shown in red). Ascending afferent input from the spinal cord might pass through relay neurons in the PAG before reaching the pontine micturition center. Note that these diagrams do not address the generation of conscious bladder sensations, or address the mechanisms that underlie the switch from storage to voluntary voiding, both of which presumably involve cerebral circuits above the PAG. R, receptors on afferent nerve terminals. Reprinted with permission from (20): Fowler CJ, Griffiths D, de Groat WC. (2008) The neural control of micturition. Nat. Rev. Neurosci. 9:453-66.

involves synaptic transmission and chemical activation of second-order spinal neurons (Figure 8) $(38,39)$. The third step would in theory involve multiple downstream mechanisms, including (a) inhibition or excitation of visceral reflex circuitry in the same segments of the cord leading to modulation of the motor outflow to the viscera or modulation of transmission of visceral sensory information to other parts of the central nervous system (Figure 8) (39-41), (b) transmission of signals to the brain to modulate supraspinal pathways controlling pelvic visceral sensory and motor mechanisms (Figure 9) and (c) initiation of reflexes in lumbosacral sympathetic or somatic efferent nerves that in turn change pelvic organ function (42).

Support for these mechanisms has been obtained in both animal and human studies. For example, experiments in pa- tients with fecal incontinence have revealed that sacral spinal nerve root stimulation (SNS) inhibits propulsive colonic motility and decreases rectal hypersensitivity, whereas in normal individuals, it enhances external sphincter excitability and increases anal electromyographic responses to cortical stimulation (2). A recent and detailed review of the literature concluded that SNS influences anorectal function by acting at the level of the pelvic afferents or in the central nervous system (6). Actions at these sites are also thought to play a major role in the treatment of urinary incontinence by SNS $(5,10,43-45)$.

An unusual and seemingly paradoxical property of SNS is its efficacy in treating constipation and idiopathic urinary retention (Fowler syndrome) by using stimulation at the same location and with the same stimulus parameters that are effective in treating bowel and bladder incontinence $(46,47)$. Fowler syndrome, which occurs mainly in women, is characterized by a loss of bladder sensations and the inability to voluntarily empty the bladder. It is associated with abnormal EUS activity and failure of the sphincter to relax during micturition. It is thought that tonic afferent firing arising in the sphincter inhibits the transmission of normal bladder sensory information to the brain (48). Functional magnetic resonance imaging (fMRI) studies revealed that SNS removes the inhibition and restores normal sensations and voiding (48). Thus, the actions of SNS can be influenced by pathological conditions. SNS can suppress abnormal sensory pathways in patients with overactive bladder but can enhance normal sensory pathways that are tonically suppressed in patients with urinary retention.

\section{EXPERIMENTAL STUDIES OF NEUROMODULATION IN ANIMAL MODELS}

\section{Mechanisms Underlying the Enhancement of Urine Storage}

The neurotransmitter mechanisms involved in neuromodulation have been 


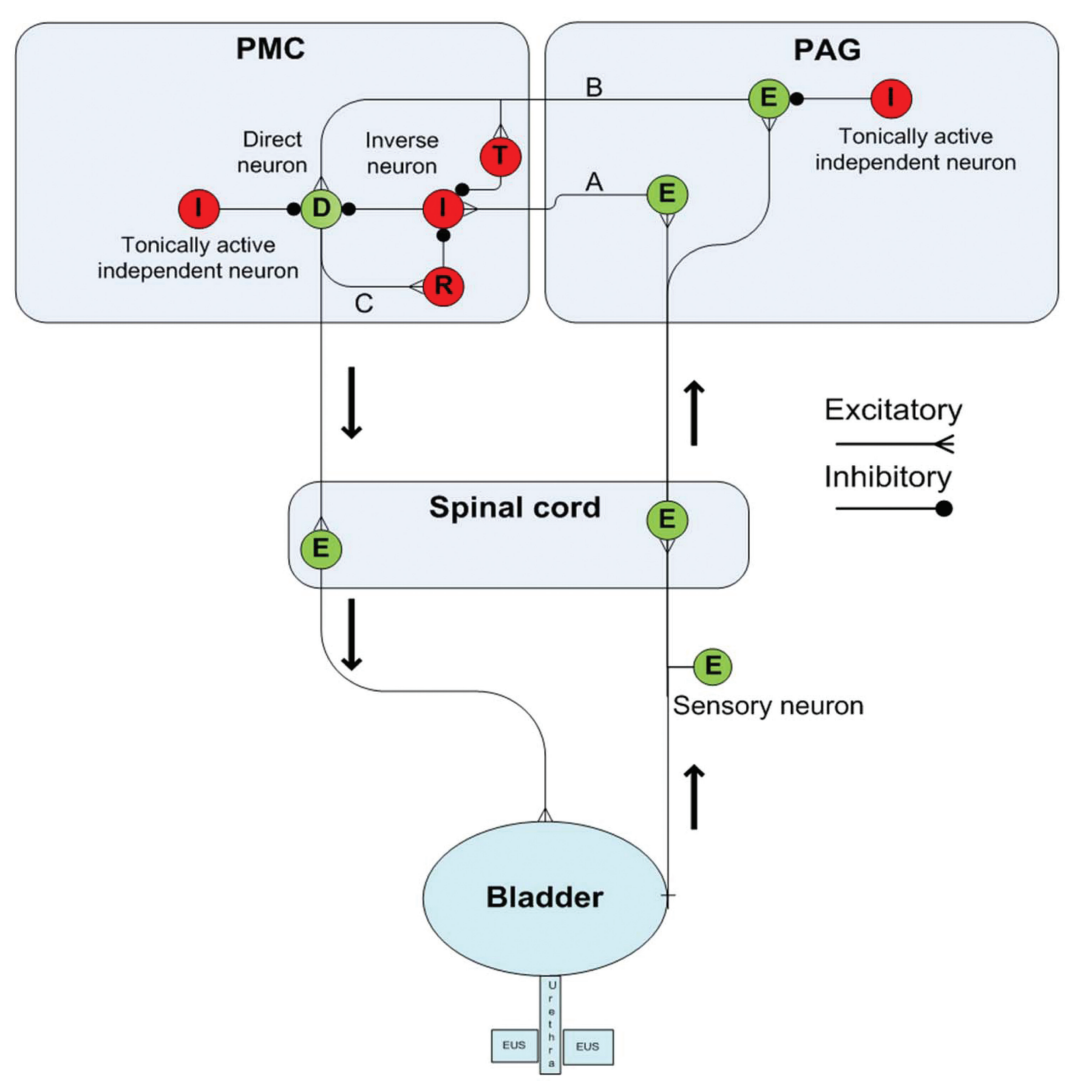

Figure 5. Computer model of PMC-PAG switching circuits. Diagram illustrating the putative pathways in the PAG and PMC that contribute to urine storage and voiding. This circuitry shows the neuronal elements and connections used in the computer model. The right side illustrates the ascending afferent limb of the spinobulbospinal micturition reflex that projects to the PAG, and the left side shows the descending limb that connects the PMC direct neuron to the bladder efferent neuron in the sacral spinal cord. During urine storage, as the bladder slowly fills, a low level of afferent activity activates an excitatory neuron (E) in the PAG, which relays information (pathway $A$ ) to an inverse neuron (I) in the PMC that in turn provides inhibitory input to the type 1 direct neuron (D) to maintain continence. Bladder afferent input is also received by a second neuron in the PAG (E) that is on the excitatory pathway (pathway B) to the PMC type 1 direct neuron (D) and to a transiently active PMC neuron (T) that fires at the beginning of micturition. However, the PAG excitatory relay neuron (E) is not activated during the early stages of bladder filling because it is inhibited by a tonically active independent neuron (I). The PMC type 1 direct neuron is also inhibited by a tonically active independent neuron (I) located in the PMC. Bladder afferent firing gradually increases during bladder filling, which increases feed-forward inhibition of the direct neuron via the PAG-PMC inverse neuron pathway. However, at a critical level of afferent firing, excitatory input to the PAG excitatory relay neuron surpasses the tonic inhibition and sends signals to the PMC transient neuron. This process briefly inhibits the inverse neuron, reducing inhibitory input to the direct neuron, allowing it to overcome tonic inhibition and fire action potentials that activate by an axon collateral (pathway $C$ ), a reciprocal inhibitory neuron (R) that suppresses the inverse neuron (I) and further reduces inhibition of the direct neuron (D). The direct neuron then switches into maximal firing mode and sends excitatory input to the spinal efferent pathway to the bladder, inducing a large bladder contraction and more afferent firing, which further enhances synaptic transmission in the PAG-PMC micturition reflex pathways. The reflex circuitry returns to storage mode as the bladder empties and afferent firing declines. Excitatory neurons are green and inhibitory neurons are red. Reprinted with permission from (31): de Groat WC, Wickens C. (2013) Organization of the neural switching circuitry underlying reflex micturition. Acta Physiol. (Oxf). 207:66-84. studied extensively in animals by using cystometry to record reflex bladder activity. In chloralose anesthetized cats with an intact central nervous system (45) and in decerebrate, unanesthetized (30) or spinal cord-transected cats $(42,49)$, bladders were infused with saline to elicit normal reflexes (50) or infused with dilute acetic acid to induce overactivity (51). The experiments compared different types of neuromodulation elicited by electrical stimulation of (a) the sacral spinal nerve root (SNS) (45), (b) the pudendal nerve $(38,40)$, (c) the posterior tibial nerve $(37,52)$, (d) the posterior cutaneous femoral nerve (53) and (e) the distal branches of tibial nerve on the plantar surface of the foot $(51,54)$. The experiments revealed that neuromodulation increases bladder capacity without altering the amplitude of reflex bladder contractions, indicating that neuromodulation suppresses the sensory/afferent limb of the micturition reflex pathway and delays the gating of the micturition switching circuit without changing the efferent limb of the reflex pathway downstream of the PAG-PMC switch (Figure 5) (31). This result is consistent with clinical data indicating that neuromodulation reduces urgency sensations and frequency of voiding without reducing voiding efficiency.

It is clear that neuromodulation of reflex bladder activity in cats depends on the action of multiple neurotransmitters in the central nervous system and that different types of neuromodulation can be identified based on stimulation parameters, site of action in the central nervous system (Figures 8 and 9) and responses to drugs. For example, pudendal nerve stimulation (PNS) and SNS neuromodulation are frequency-dependent and are effective at low frequencies of stimulation $(5-10 \mathrm{~Hz})$ but not at higher frequencies $(20-30 \mathrm{~Hz})(45,55)$, whereas posterior tibial nerve stimulation (TNS) or foot stimulation is effective across a broader range of frequencies $(5-30 \mathrm{~Hz})$ $(50,51)$. PNS neuromodulation is only effective during the period of stimulation and the effect is lost within a few minutes 


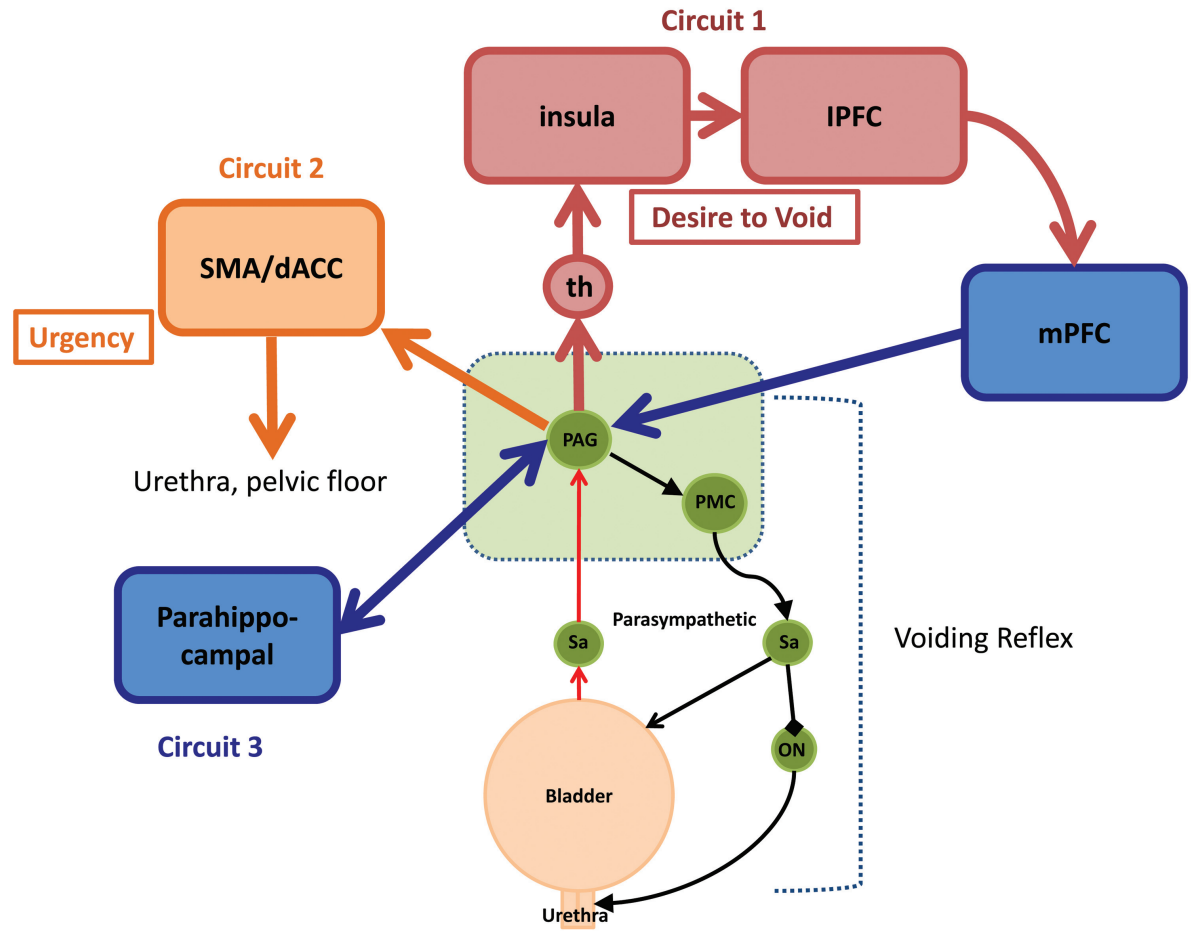

Figure 6. A simple working model of the lower urinary tract control system, showing the voiding reflex and brainstem (green) and forebrain circuits 1, 2 and 3 (red/blue, yellow and blue, respectively). Circuit 1 includes the thalamus (th) and insula, which is regarded as the homeostatic afferent cortex. The insula processes visceral sensations and sends information about the state of the bladder to the medial prefrontal cortex (mPFC), which is thought to provide modulatory feedback to PAG-PMC circuits. Lesions in the MPFC can induce incontinence. Circuit 2 includes the dorsal anterior cingulate cortex (dACC) and the supplementary motor area (SMA), which are thought to be involved in motivation and modulation of body arousal states. These areas are activated when patients experience a sense of urinary urgency and are thought to trigger responses of the urethral outlet to postpone voiding. Circuit 3 is thought to be concerned with the emotional aspects of voiding. IPFC, lateral prefrontal cortex. Reprinted with permission from (1): de Groat WC, Griffiths D, Yoshimura N. (2015) Neural control of the lower urinary tract. Compr. Physiol. 5:327-96. doi: 10.1002/cphy.c130056.

after termination of the stimulation $(38,56,57)$, whereas the inhibitory effect of TNS or foot stimulation persists for at least $2 \mathrm{~h}$ after termination of the stimulation but only in normal bladders and not in irritated bladders $(58,59)$.

The effect of PNS neuromodulation depends in part on inhibitory transmission in the spinal cord mediated by gamma aminobuyric acid (GABA) (Figure 8 ) and is suppressed by a GABA $\mathrm{A}$ receptor antagonist (picrotoxin) $(39,40)$ but not by an opioid receptor antagonist (naloxone) $(42,56,60)$. However, the effect of tibial nerve stimulation or foot stimu- lation on bladder overactivity is suppressed by naloxone, an opioid receptor antagonist, and therefore involves opioid receptor mechanisms $(54,61)$. In addition, the inhibitory effect of TNS on normal bladder activity is not suppressed by naloxone, indicating that the mechanism of modulation by TNS can be altered by pathological conditions (50). The inhibitory effect of PNS exists in acute and chronic spinal transected animals (T8-T9) (39-41,55,57), whereas the effect of TNS is not detectable in acute spinal transected animals (41) but is present in decerebrate animals, raising the possibil- ity that TNS suppresses micturition by an action on the PAG-PMC circuits (Figure 9). Thus, the two types of inhibition target different sites in the central nervous system. The effect of PNS is reduced by transecting the hypogastric nerves or administration of a nonselective $\beta$ adrenergic receptor antagonist $(42,62)$, whereas the effect of SNS is not affected by these procedures (45), indicating that PNS inhibition but not SNS inhibition is mediated in part by reflex activation of sympathetic inhibitory pathways to the bladder.

PNS neuromodulation that remains after propranolol treatment is also suppressed by administration of MTEP, a metabotropic glutamate receptor 5 (mGluR5) antagonist $(38,56)$. This effect occurs in both spinal cord intact and acute spinal cord transected animals, indicating as shown in Figure 8 that pudendal neuromodulation may be mediated by a spinal disynaptic inhibitory pathway consisting of an initial mGluR5 excitatory synapse that activates GABAergic inhibitory input to the spinal micturition reflex pathway. TNS inhibition is reduced by an mGluR2/3 antagonist (LY341495), indicating that a different type of glutamatergic excitatory transmission is necessary for activation of the TNS opioid inhibitory mechanism (61).

PNS suppresses the bladder contractions elicited by electrical stimulation of the PMC, suggesting that the PNS inhibition influences the descending efferent limb of the spinal-brain-spinal micturition pathway (Figure 8). PNS inhibition is also modulated by bulbospinal serotonergic pathways because the inhibition can be suppressed by methysergide, an antagonist of serotoninergic $5 \mathrm{HT}_{2}$ receptors (63), and by ondansetron, an antagonist of $5 \mathrm{HT}_{3}$ receptors (64). Duloxetine, a serotonin/norepinephrine reuptake inhibitor known to increase serotonin levels in the raphe nuclei and enhance serotonin autoinhibition of raphe neuron firing by activation of $5 \mathrm{HT}_{1 \mathrm{~A}}$ receptors, also suppresses PNS inhibition (65). WAY100635, a $5 \mathrm{HT}_{1 \mathrm{~A}}$ receptor antagonist, reverses the duloxetine inhibitory effect and enhances 


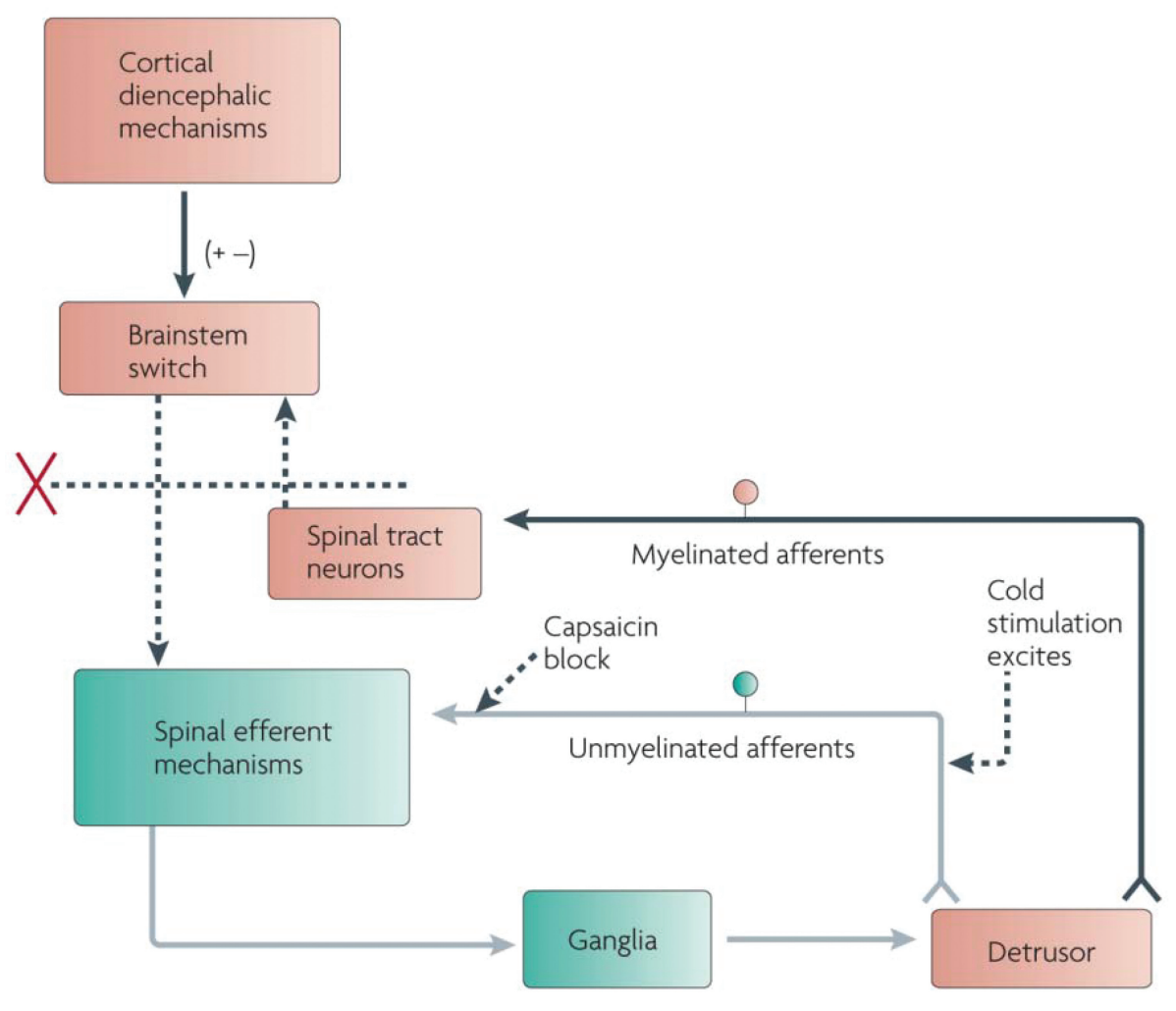

Figure 7. Changes in the organization of the parasympathetic excitatory reflex pathway to the detrusor muscle after spinal cord injury. This scheme is based on results from electrophysiological studies in cats. In spinal intact animals, micturition is initiated by a supraspinal reflex pathway that passes through a center in the brainstem. The pathway is triggered by myelinated afferents (A $\delta$-fibers), which are connected to the tension receptors in the bladder wall. Injury to the spinal cord above the sacral segments interrupts the connections between the brain and spinal autonomic centers and initially blocks micturition. However, after cord injury, a spinal reflex mechanism (shown in green) emerges that is triggered by unmyelinated vesical afferents (C-fibers); the A-fiber afferent inputs are ineffective. The C-fiber reflex pathway is usually weak or undetectable in animals with an intact nervous system. Stimulation of the C-fiber bladder afferents by instillation of ice water into the bladder (cold stimulation) activates voiding responses in patients with spinal cord injury. Capsaicin (20-30 mg, subcutaneously) blocks the C-fiber reflex in cats with spinal lesions but does not block micturition reflexes in spinal intact cats. Intravesical capsaicin also suppresses detrusor hyperreflexia and cold-evoked reflexes in patients with neurogenic bladder dysfunction. Reprinted with permission from (20): Fowler CJ, Griffiths D, de Groat WC. (2008) The neural control of micturition. Nat. Rev. Neurosci. 9:453-66.

PNS inhibition (65). These data suggest that tonic bulbospinal serotonergic input facilitates the PNS inhibitory pathway, and removal of this input suppresses the inhibitory pathway. A combination of duloxetine and WAY100635 also enhanced bladder inhibition elicited by foot stimulation (66). These studies demonstrate the potential complexity of neuromodulatory inhibitory mechanisms and show that to fully understand neuromodulation, it will be necessary to identify the contributions of multiple neurotransmitters.

\section{TREATMENT OF LOWER URINARY TRACT DYSFUNCTION AFTER SPINAL CORD INJURY}

Spinal cord injury rostral to the lumbosacral level eliminates voluntary and supraspinal control of voiding, leading initially to an areflexic bladder and complete urinary retention, followed by slow development of automatic micturition and bladder overactivity mediated by spinal reflex pathways (Figure 7$)(1,36)$. However, voiding is commonly inefficient because of simultaneous contractions of the bladder and urethral sphincter (detrusor-sphincter-dyssynergia [DSD]). Thus, the bladder does not store well or empty well after spinal injury.

Sacral anterior root stimulation in combination with sacral deafferentation was developed in the 1970s to treat this condition (16). Transection of the sacral posterior roots eliminates reflex contractions of the sphincter and DSD, while electrical stimulation of the anterior roots activates the parasympathetic efferent pathway to the bladder, producing bladder emptying. Stimulating electrodes are connected to a radio receiver positioned subcutaneously over the lower chest wall and activated by an external radio transmitter to induce micturition. The method has also been used to elicit defecation and penile erection. However, this device can only be used in individuals with complete suprasacal injuries because the stimulation produces pain when the spinal injury is incomplete. Another disadvantage that has limited widespread use is that posterior rhizotomy interrupts reflex functions of the pelvic viscera, including penile erections.

In people with complete suprasacral spinal cord injury, SNS has not been effective in reducing detrusor overactivity, suggesting that spinal reflex mechanisms are more resistant to this inhibition (67). However, a recent study (67) in which bilateral SNS was begun during the early acute bladder areflexic phase following complete spinal cord injury revealed that the SNS prevented the development of detrusor overactivity and urinary incontinence, normalized bladder capacity, reduced urinary tract infection rates and improved bowel function. The mean follow-up was 26 months. The beneficial effects did not occur with unilateral sacral neuromodulation. These results raise the possibility that early application of SNS influences the reorganization of spinal circuits that occurs after disruption of de- 


\section{PNS Inhibition of Bladder Overactivity}

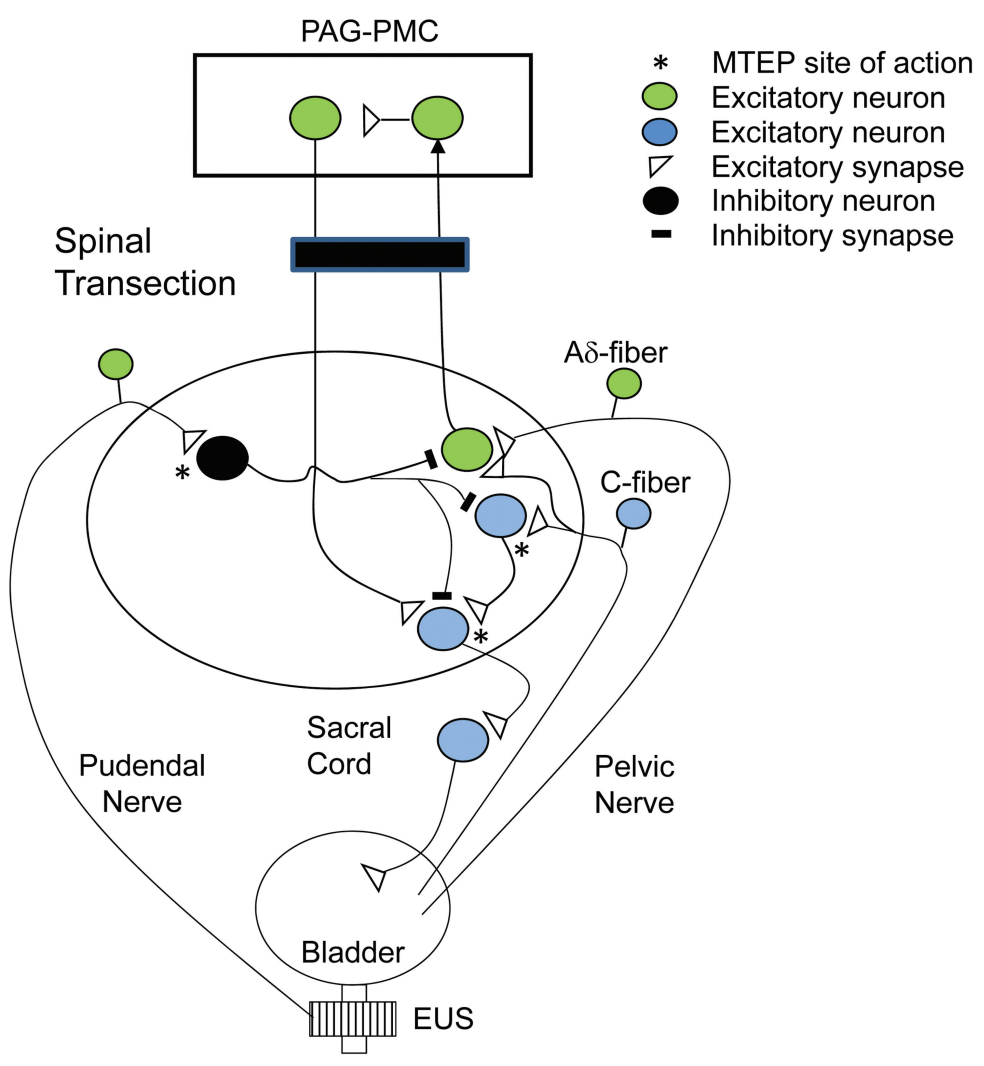

Figure 8. Model showing putative circuitry and neurotransmitters involved in the inhibition of reflex bladder overactivity elicited by pudendal nerve stimulation (PNS) in an acute spinal cord transected cat (T9/T10). Bladder overactivity was elicited by intravesical infusion of dilute acetic acid. Pudendal nerve afferents (right side) activate a GABA inhibitory interneuron via the release of glutamate and stimulation of metabotropic glutamate receptor 5 (mGluR5). The GABA interneuron can suppress the C-fiber afferent-mediated spinal micturition reflex by inhibiting transmission at the level of an excitatory interneuron or the preganglionic neuron. Note the supraspinal micturition reflex activated by Ad afferents is eliminated by spinal cord transection. GABA activates $G_{A B A}$ receptors, which are blocked by picrotoxin. Excitatory glutamatergic transmission at the pudendal afferent terminal or in the micturition reflex pathway $\left(^{*}\right)$ is blocked by MTEP, an mGluR5 antagonist.

scending spinal tracts and reduces the neuroplasticity that underlies the emergence of neurogenic detrusor overactivity.

Experiments in chronic spinal cord-injured cats have evaluated the efficacy of different frequencies of PNS for promoting voiding $(49,55,57)$. Whereas low frequencies $(5-10 \mathrm{~Hz})$ of stimulation suppress reflex bladder contractions, higher frequencies $(20-40 \mathrm{~Hz})$ produce large amplitude reflex contractions. Electrical stimulation of pudendal sensory nerve branches to the penis, clitoris or urethra also elicit reflex bladder contractions in animals and humans (13,68-75). However, voiding efficiency is low $(10 \%)$ because of simultaneous contractions of the EUS due to direct stimulation of sphincter motor axons in the pudendal nerve or EUS reflex responses induced by the rise in intravesical pressure and activation of bladder afferents. However, voiding can be improved considerably (to $90 \%$ ) by blocking the motor input to the sphincter by applying ultrahigh frequency stimulation $(5-20 \mathrm{kHz})$ to the pudendal nerve to block conduction in the sphincter motor axons distal to the site of the pudendal afferent stimulation used to elicit the bladder contractions $(57,76)$. The axonal block induced by ultrahigh frequency stimulation is rapidly reversible and repeatable $(77,78)$.

Modulation of lower urinary tract function has also been induced by stimulation and block of pudendal nerve axons by using a wireless-controlled implantable stimulator in cats (79). Tripolar cuff electrodes were implanted bilaterally on the pudendal nerves to block motor pathways to the EUS, and a bipolar cuff electrode was implanted proximal to the tripolar electrodes to activate pudendal afferent input to the spinal cord. Continence promoting responses such as an increased bladder capacity and an increase in urethral pressure due to sphincter contractions were elicited by low-frequency $(5 \mathrm{~Hz})$ afferent and efferent stimulation. Responses that could be used to induce voiding such as an increase in intravesical pressure and sphincter relaxation were induced by 20-30 Hz stimulation of the bipolar electrode and $5-10 \mathrm{kHz}$ stimulation of the blocking electrodes. Although the mechanisms involved in ultrahigh frequency axonal block are still uncertain (80-85), it is likely that this method in combination with low frequency stimulation will be useful for modulating neurogenic lower urinary tract dysfunction. Other approaches for selectively modulating bladder and sphincter activity in individuals with spinal cord injury include activation of afferent nerves with different patterns of stimulation or stimulation of subpopulations of afferent axons in distal branches of the pudendal nerve that may have more specific reflex functions (68-70,73-75).

\section{FUTURE DIRECTIONS}

Questions to be addressed in future research include (a) can mechanisms of action of neuromodulation of pelvic organ dysfunction identified in anesthetized animal models be validated in humans, (b) do certain types of neuromodulation 


\section{TNS Inhibition of Bladder Overactivity}

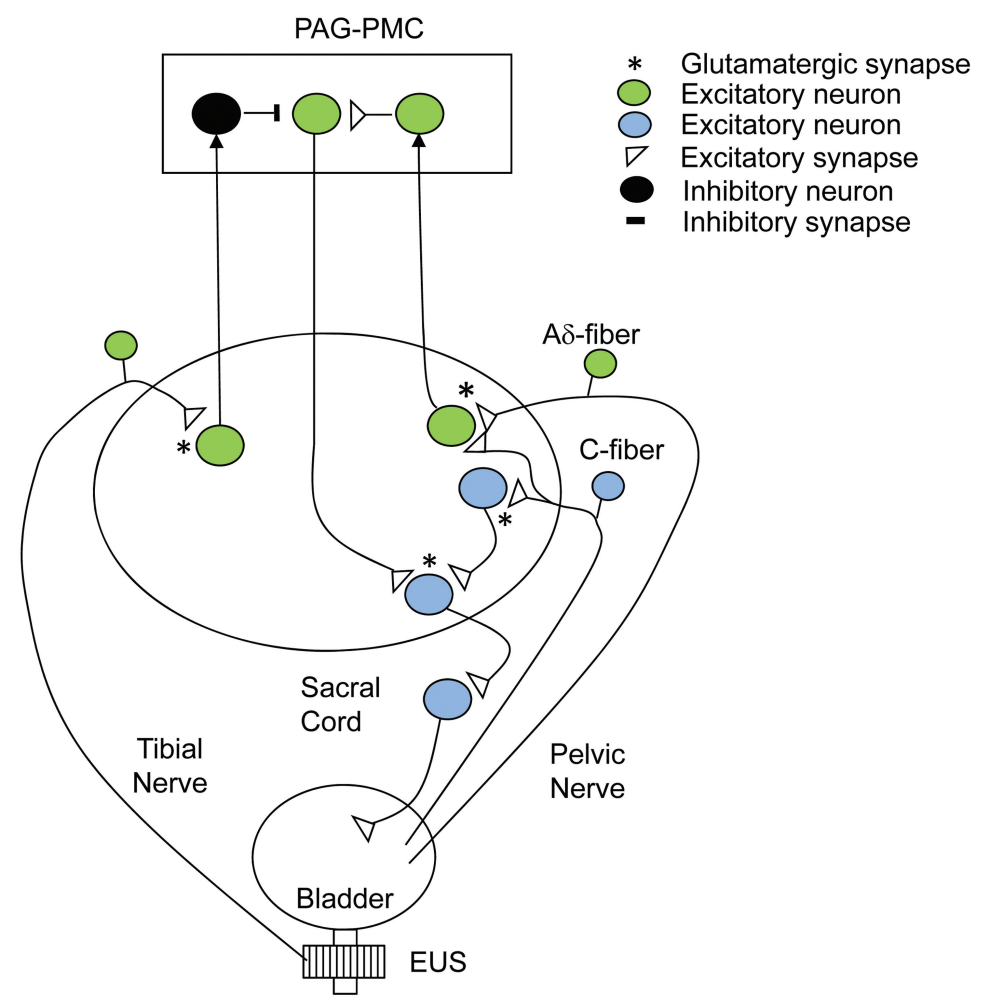

Figure 9. Model showing putative circuitry and neurotransmitters involved in inhibition of reflex bladder overactivity elicited by TNS in a cat with an intact spinal cord. Bladder overactivity is elicited by intravesical infusion of dilute acetic acid and is mediated by both spinal and supraspinal pathways triggered by both A $\delta$ and C-fiber bladder afferents. Note that TNS does not inhibit reflex bladder activity in the acute spinal cord transected preparation shown in Figure 8. It is likely that the inhibition occurs at a supraspinal site. Tibial nerve afferents activate (presumably by the releases of glutamate and stimulation of glutamatergic receptors) a spinal tract neuron that transmits information to the brain (left side). The receptors may be mGluR2/3 subtypes because LY341495, an mGluR2/3 antagonist, suppresses TNS inhibition. Because naloxone, an opioid receptor antagonist, blocks TNS inhibition, it is likely that the inhibition of the supraspinal micturition reflex pathway occurs at the level of the PAG-PMC and is mediated by release of an opioid peptide. Activation of opioid receptors in the brain with drugs suppresses reflex bladder activity, and intracerebroventricular injection of naloxone enhances bladder reflexes, indicating that the reflexes are tonically suppressed by endogenously released opioid peptides. *Excitatory glutamatergic transmission at the tibial nerve afferent terminal or in the micturition reflex pathway in the spinal cord.

produce slowly developing, prolonged changes in neural control (that is, neuroplasticity) that persist after termination of the stimulation, (c) does neuromodulation only affect symptoms or can it alter the development or progression of pathophysiological mechanisms, (d) does stimulation of specific subpopulations of afferent axons in distal nerve branches in contrast to stimulation of heterogeneous afferent populations in large nerve trunks produce more effective control of symptoms, (e) can simultaneous stimulation of multiple nerves that act by different mechanisms produce greater efficacy, and (f) can a combination of drug therapy and nerve stimulation produce greater efficacy?
The possibility of combination therapies is theoretically appealing because the animal experiments revealed that diverse chemical signals (that is, neurotransmitters) are involved in neuromodulation. This raises the possibility that drugs targeting these chemical signaling mechanisms might be used to enhance the efficacy of neuromodulation. In addition, synergistic interactions between drugs and neuromodulation may enhance drug efficacy and thereby allow a reduction in drug dosage and side effects. The animal study in which WAY100635, a $5 \mathrm{HT}_{1 \mathrm{~A}}$ receptor antagonist, enhanced pudendal neuromodulation is an example of the potential benefits of combination therapy (65). Similarly, because GABA is an important inhibitory transmitter for pudendal neuromodulation $(39,40)$, it is possible that drugs that increase GABA concentrations at the synapse by blocking GABA reuptake/metabolism or drugs that act allosterically with the $\mathrm{GABA}_{\mathrm{A}}$ receptors to enhance GABAergic inhibition would be useful in combination therapies. Similar approaches might be used to enhance neuromodulation induced by TNS or foot stimulation, which suppress bladder overactivity by activating opioid receptor mechanisms $(54,61)$. Animal experiments showed that administration of tramadol, an opioid receptor agonist with monoamine reuptake inhibitor properties, enhances the bladder inhibitory effects of these two types of neuromodulation and unmasks a prolonged suppression of bladder overactivity that persists after termination of the electrical stimulation $(86,87)$. Thus, future clinical studies should examine the interactions between pharmaceuticals and electroceuticals. Furthermore, if it is reasonable to assume that neuromodulation and drugs act by reversing pathological mechanisms, then these experiments may provide insights into the pathophysiology of pelvic visceral disorders and lead to the identification of molecular targets for new therapies.

\section{DISCLOSURE}

The authors declare that they have no competing interests as defined by Bioelec- 
tronic Medicine, or other interests that might be perceived to influence the results and discussion reported in this paper.

\section{REFERENCES}

1. de Groat WC, Griffiths D, Yoshimura N. (2015) Neural control of the lower urinary tract. Compr. Physiol. 5:327-96.

2. Gourcerol G, et al. (2011) How sacral nerve stimulation works in patients with faecal incontinence. Colorectal Dis. 13:203-11.

3. Marson L. (2011) Autonomic regulation of sexual function. In: Central Regulation of Autonomic Functions. Llewellyn-Smith IJ, Verberne AJ (eds.) New York, Oxford University Press, pp. 366-81.

4. Andersson KE, et al. (2009) Pharmacological treatment of urinary incontinence. In: Incontinence. Abrams P, Cardozo L, Khoury S, Wein A (eds.). Plymouth, UK, Health Publication, pp. 631-700.

5. Bartley J, Gilleran J, Peters K. (2013) Neuromodulation for overactive bladder. Nat. Rev. Urol. 10:513-21.

6. Carrington EV, et al. (2014) A systematic review of sacral nerve stimulation mechanisms in the treatment of fecal incontinence and constipation. Neurogastroenterol. Motil. 26:1222-37.

7. Noblett KL, Cadish LA. (2014) Sacral nerve stimulation for the treatment of refractory voiding and bowel dysfunction. Am. J. Obstet. Gynecol. 210:99-106.

8. Staskin DR, Peters KM, MacDiarmid S, Shore N, de Groat WC. (2012) Percutaneous tibial nerve stimulation: a clinically and cost effective addition to the overactive bladder algorithm of care. Curr. Urol. Rep. 13:327-34.

9. Ammi M, et al. (2014) Transcutaneous posterior tibial nerve stimulation: evaluation of a therapeutic option in the management of anticholinergic refractory overactive bladder. Int. Urogynecol. J. 25:1065-9.

10. Peters KM, Killinger KA, Boguslawski BM, Boura JA. (2010) Chronic pudendal neuromodulation: expanding available treatment options for refractory urologic symptoms. Neurourol. Urodyn. 29:1267-71.

11. Chen ML, et al. (2014) Electrical stimulation of somatic afferent nerves in the foot increases bladder capacity in healthy human subjects. J. Urol. 191:1009-13.

12. Gladh G, Mattsson S, Lindstrom S. (2003) Intravesical electrical stimulation in the treatment of micturition dysfunction in children. Neurourol. Urodyn. 22:233-42.

13. Yoo PB, Horvath EE, Amundsen CL, Webster GD, Grill WM. (2009) Intraurethral activation of excitatory bladder reflexes in persons with spinal cord injury. Conf. Proc. IEEE Eng. Med. Biol. Soc. 2009:6781-4.

14. Opisso E, Borau A, Rijkhoff NJ. (2013) Subjectcontrolled stimulation of dorsal genital nerve to treat neurogenic detrusor overactivity at home. Neurourol. Urodyn. 32:1004-9.

15. Goldman HB, et al. (2008) Dorsal genital nerve stimulation for the treatment of overactive bladder symptoms. Neurourol. Urodyn. 27:499-503.

16. Brindley GS. (1994) The first 500 patients with sacral anterior root stimulator implants: general description. Paraplegia. 32:795-805.

17. de Groat WC, Booth AM. (1993) Synaptic transmission in pelvic ganglia. In: Nervous Control of the Urogenital System. Maggi CA (ed.). London, UK, Harwood Academic Publishers, pp. 291-347.

18. Keast JR. (1999) Unusual autonomic ganglia: connections, chemistry, and plasticity of pelvic ganglia. Int. Rev. Cytol. 193:1-69.

19. Thor KB, de Groat WC. (2010) Neural control of the female urethral and anal rhabdosphincters and pelvic floor muscles. Am. J. Physiol. Regul. Integr. Comp. Physiol. 299:R416-38.

20. Fowler CJ, Griffiths D, de Groat WC. (2008) The neural control of micturition. Nat. Rev. Neurosci. 9:453-66.

21. de Groat WC, Yoshimura N. (2009) Afferent nerve regulation of bladder function in health and disease. Handb. Exp. Pharmacol. 194:91-138.

22. Araki I. (1994) Inhibitory postsynaptic currents and the effects of GABA on visually identified sacral parasympathetic preganglionic neurons in neonatal rats. J. Neurophysiol. 72:2903-10.

23. Araki I, de Groat WC. (1996) Unitary excitatory synaptic currents in preganglionic neurons mediated by two distinct groups of interneurons in neonatal rat sacral parasympathetic nucleus. J. Neurophysiol. 76:215-26.

24. Vizzard MA, Erickson VL, Card JP, Roppolo JR, de Groat WC. (1995) Transneuronal labeling of neurons in the adult rat brainstem and spinal cord after injection of pseudorabies virus into the urethra. J. Comp. Neurol. 355:629-40.

25. Beckel JM, Holstege G. (2011) Neurophysiology of the lower urinary tract. Handb. Exp. Pharmacol. 202:149-69.

26. Birder LA, Roppolo JR, Erickson VL, de Groat WC. (1999) Increased c-fos expression in spinal lumbosacral projection neurons and preganglionic neurons after irritation of the lower urinary tract in the rat. Brain Res. 834:55-65.

27. Steers WD, Mallory B, de Groat WC. (1988) Electrophysiological study of neural activity in penile nerve of the rat. Am. J. Physiol. 254:R989-1000.

28. Barrington F. (1925) The effect of lesions of the hind- and mid-brain on micturition in the cat. Quart. J. Exp. Physiol. 15:81-102.

29. de Groat WC. (1975) Nervous control of the urinary bladder of the cat. Brain Res. 87:201-11.

30. de Groat WC, Ryall RW. (1969) Reflexes to sacral parasympathetic neurones concerned with micturition in the cat. J. Physiol. 200:87-108.

31. de Groat WC, Wickens C. (2013) Organization of the neural switching circuitry underlying reflex micturition. Acta Physiol. (Oxf). 207:66-84.

32. de Groat WC, Krier J. (1979) The central control of the lumbar sympathetic pathway to the large intestine of the cat. J. Physiol. 289:449-68.

33. de Groat WC, Krier J. (1978) The sacral parasympathetic reflex pathway regulating colonic motility and defaecation in the cat. J. Physiol. 276:481-500.
34. Shimizu Y, et al. (2006) Evidence that stimulation of ghrelin receptors in the spinal cord initiates propulsive activity in the colon of the rat. J. Physiol. 576:329-38.

35. Rouzade-Dominguez ML, Miselis R, Valentino RJ. (2003) Central representation of bladder and colon revealed by dual transsynaptic tracing in the rat: substrates for pelvic visceral coordination. Eur. J. Neurosci. 18:3311-24.

36. de Groat WC, Yoshimura N. (2012) Plasticity in reflex pathways to the lower urinary tract following spinal cord injury. Exp. Neurol. 235:123-32.

37. Tai C, et al. (2011) Irritation induced bladder overactivity is suppressed by tibial nerve stimulation in cats. J. Urol. 186:326-30.

38. Larson JA, et al. (2011) Involvement of metabotropic glutamate receptor 5 in pudendal inhibition of nociceptive bladder activity in cats. J. Physiol. 589:5833-43.

39. Xiao Z, et al. (2014) Role of spinal GABAA receptors in pudendal inhibition of nociceptive and nonnociceptive bladder reflexes in cats. Am. J. Physiol. Renal Physiol. 306:F781-9.

40. McGee MJ, Danziger ZC, Bamford JA, Grill WM. (2014) A spinal GABAergic mechanism is necessary for bladder inhibition by pudendal afferent stimulation. Am. J. Physiol. Renal Physiol. 307:F921-30.

41. Xiao Z, et al. (2014) Somatic modulation of spinal reflex bladder activity mediated by nociceptive bladder afferent nerve fibers in cats. Am. J. Physiol. Renal Physiol. 307:F673-9.

42. Rogers MJ, et al. (2015) Propranolol, but not naloxone, enhances spinal reflex bladder activity and reduces pudendal inhibition in cats. Am. J. Physiol. Regul. Integr. Comp. Physiol. 308:R42-9.

43. Su X, Nickles A, Nelson DE. (2013) Role of the endogenous opioid system in modulation of urinary bladder activity by spinal nerve stimulation. Am. J. Physiol. Renal Physiol. 305:F52-60.

44. Wang Y, Hassouna MM. (2000) Neuromodulation reduces c-fos gene expression in spinalized rats: a double-blind randomized study. J. Urol. 163:1966-70.

45. Zhang F, et al. (2013) Neural pathways involved in sacral neuromodulation of reflex bladder activity in cats. Am. J. Physiol. Renal Physiol. 304:F710-7.

46. DasGupta R, Fowler CJ. (2003) The management of female voiding dysfunction: Fowler's syndrome: a contemporary update. Curr. Opin. Urol. 13:293-9.

47. Osman NI, Chapple CR. (2014) Fowler's syndrome: a cause of unexplained urinary retention in young women? Nat. Rev. Urol. 11:87-98.

48. Kavia R, Dasgupta R, Critchley H, Fowler C, Griffiths D. (2010) A functional magnetic resonance imaging study of the effect of sacral neuromodulation on brain responses in women with Fowler's syndrome. BJU Int. 105:366-72.

49. Tai C, et al. (2011) Plasticity of urinary bladder reflexes evoked by stimulation of pudendal afferent nerves after chronic spinal cord injury in cats. Exp. Neurol. 228:109-17.

50. Tai C, et al. (2012) Differential role of opioid receptors in tibial nerve inhibition of nociceptive 
and nonnociceptive bladder reflexes in cats. Am. J. Physiol. Renal Physiol. 302:F1090-7.

51. Tai C, et al. (2011) Suppression of bladder overactivity by activation of somatic afferent nerves in the foot. BJU Int. 107:303-9.

52. Tai C, et al. (2011) Prolonged poststimulation inhibition of bladder activity induced by tibial nerve stimulation in cats. Am. J. Physiol. Renal Physiol. 300:F385-92.

53. Tai C, et al. (2012) Inhibition of micturition reflex by activation of somatic afferents in posterior femoral cutaneous nerve. J. Physiol. 590:4945-55.

54. Tai C, et al. (2012) Involvement of opioid receptors in inhibition of bladder overactivity induced by foot stimulation in cats. J. Urol. 188:1012-6.

55. Tai C, Smerin SE, de Groat WC, Roppolo JR. (2006) Pudendal-to-bladder reflex in chronic spinal-cord-injured cats. Exp. Neurol. 197:225-34.

56. Mally AD, et al. (2013) Role of opioid and metabotropic glutamate 5 receptors in pudendal inhibition of bladder overactivity in cats. J. Urol. 189:1574-9.

57. Tai C, Wang J, Wang X, de Groat WC, Roppolo JR. (2007) Bladder inhibition or voiding induced by pudendal nerve stimulation in chronic spinal cord injured cats. Neurourol. Urodyn. 26:570-7.

58. Chen G, et al. (2012) Post-stimulation inhibitory effect on reflex bladder activity induced by activation of somatic afferent nerves in the foot. J. Urol. 187:338-43.

59. Matsuta Y, Roppolo JR, de Groat WC, Tai C. (2014) Poststimulation inhibition of the micturition reflex induced by tibial nerve stimulation in rats. Physiol. Rep. 2:e00205.

60. Chen ML, et al. (2010) Influence of naloxone on inhibitory pudendal-to-bladder reflex in cats. Exp. Neurol. 224:282-91.

61. Matsuta Y, et al. (2013) Contribution of opioid and metabotropic glutamate receptor mechanisms to inhibition of bladder overactivity by tibial nerve stimulation. Am. J. Physiol. Regul. Integr. Comp. Physiol. 305:R126-33.

62. Woock JP, Yoo PB, Grill WM. (2011) Mechanisms of reflex bladder activation by pudendal afferents. Am. J. Physiol. Regul. Integr. Comp. Physiol. 300:R398-407.

63. Matsuta Y, et al. (2013) Effect of methysergide on pudendal inhibition of micturition reflex in cats. Exp. Neurol. 247:250-8.

64. Schwen Z, et al. (2013) Involvement of 5-HT3 receptors in pudendal inhibition of bladder overactivity in cats. Am. J. Physiol. Renal Physiol. 305:F663-71.

65. Reese J, et al. (2014) Effects of duloxetine and WAY100635 on pudendal inhibition of bladder overactivity in cats. J. Pharmacol. Exp. Ther. 349:402-7.

66. Schwen Z, et al. (2013) Inhibition of bladder overactivity by duloxetine in combination with foot stimulation or WAY-100635 treatment in cats. Am. J. Physiol. Renal Physiol. 305:F1663-8.

67. Sievert KD, et al. (2010) Early sacral neuromodulation prevents urinary incontinence after complete spinal cord injury. Ann. Neurol. 67:74-84.

68. Kennelly MJ, et al. (2010) Electrical stimulation of the urethra evokes bladder contractions in a woman with spinal cord injury. J. Spinal Cord. Med. 33:261-5.

69. Kennelly MJ, Bennett ME, Grill WM, Grill JH, Boggs JW. (2011) Electrical stimulation of the urethra evokes bladder contractions and emptying in spinal cord injury men: case studies. J. Spinal Cord Med. 34:315-21.

70. McGee MJ, Amundsen CL, Grill WM. (2015) Electrical stimulation for the treatment of lower urinary tract dysfunction after spinal cord injury. J. Spinal Cord Med. 38:135-46.

71. McGee MJ, Grill WM. (2014) Selective costimulation of pudendal afferents enhances bladder activation and improves voiding efficiency. Neurourol. Urodyn. 33:1272-8.

72. Wang J, et al. (2009) Bladder inhibition or excitation by electrical perianal stimulation in a cat model of chronic spinal cord injury. BJU Int. 103:530-6.

73. Yoo PB, Horvath EE, Amundsen CL, Webster GD Grill WM. (2011) Multiple pudendal sensory pathways reflexly modulate bladder and urethral activity in patients with spinal cord injury. J. Urol. 185:737-43.

74. Yoo PB, Woock JP, Grill WM. (2008) Bladder activation by selective stimulation of pudendal nerve afferents in the cat. Exp. Neurol. 212:218-25.

75. Tai C, et al. (2008) Inhibitory and excitatory perigenital-to-bladder spinal reflexes in the cat. Am. J. Physiol. Renal Physiol. 294:F591-602.

76. Tai C, Wang J, Wang X, Roppolo JR, de Groat WC. (2007) Voiding reflex in chronic spinal cord injured cats induced by stimulating and blocking pudendal nerves. Neurourol. Urodyn. 26:879-86.

77. Tai C, Roppolo JR, de Groat WC. (2004) Block of external urethral sphincter contraction by high frequency electrical stimulation of pudendal nerve. J. Urol. 172:2069-72.

78. Tai C, Roppolo JR, de Groat WC. (2005) Response of external urethral sphincter to high frequency biphasic electrical stimulation of pudendal nerve. J. Urol. 174:782-6.

79. Yang G, et al. (2014) Pudendal nerve stimulation and block by a wireless-controlled implantable stimulator in cats. Neuromodulation. 17:490-6.

80. Liu H, Roppolo JR, de Groat WC, Tai C. (2009) Modulation of axonal excitability by high-frequency biphasic electrical current. IEEE Trans. Biomed. Eng. 56:2167-76.

81. Liu H, Roppolo JR, de Groat WC, Tai C. (2009) The role of slow potassium current in nerve conduction block induced by high-frequency biphasic electrical current. IEEE Trans. Biomed. Eng. 56:137-46.

82. Wang J, Shen B, Roppolo JR, de Groat WC, Tai C. (2008) Influence of frequency and temperature on the mechanisms of nerve conduction block induced by high-frequency biphasic electrical current. J. Comput. Neurosci. 24:195-206.

83. Kilgore KL, Bhadra N. (2014) Reversible nerve conduction block using kilohertz frequency alternating current. Neuromodulation. 17:242-54.

84. Zhao S, et al. (2014) Effect of non-symmetric waveform on conduction block induced by highfrequency $(\mathrm{kHz})$ biphasic stimulation in unmyelinated axon. J. Comput. Neurosci. 37:377-86.

85. Zhang X, Roppolo JR, de Groat WC, Tai C. (2006) Simulation analysis of conduction block in myelinated axons induced by high-frequency biphasic rectangular pulses. IEEE Trans. Biomed. Eng. 53:1433-6.

86. Mally AD, et al. (2012) Combination of foot stimulation and tramadol treatment reverses irritation induced bladder overactivity in cats. J. Urol. 188:2426-32.

87. Zhang F, et al. (2012) Inhibition of bladder overactivity by a combination of tibial neuromodulation and tramadol treatment in cats. Am. J. Physiol. Renal Physiol. 302:F1576-82.

Cite this article as: de Groat WC, Tai C. (2015) Impact of bioelectronic medicine on the neural regulation of pelvic visceral function. Bioelectron. Med. 2:25-36. 